\title{
REGULAÇÃO PRÓ-CONCORRENCIAL E O NOVO CICLO DE ABERTURA COMERCIAL NO BRASIL
}

\author{
Gesner Oliveira \\ FGV-EAESP
}

O objetivo deste ensaio é avaliar se o aparato regulatório brasileiro tem sido um obstáculo ou um incentivo ao comércio e ao investimento. Em termos gerais, apesar de a regulação ter impactos ambíguos sobre o investimento, a regulação pró-competitiva gera inversões e diminui barreiras ao comércio. Por sua vez, a adoção de critérios de defesa da concorrência na defesa comercial também teria efeitos positivos no esforço de maior acesso a mercados.

O ensaio está organizado da seguinte forma: a primeira seção contextualiza o novo ciclo de abertura comercial que o Brasil atravessa e trata da relação entre regulação e investimento; a seção seguinte discute a relação entre modelos regulatórios e as barreiras ao comércio. À luz dos pontos discutidos, a terceira seção faz considerações acerca dos anteprojetos recentemente submetidos à consulta pública pelo Poder Executivo, que visam realizar mudanças nas agências reguladoras. A quarta seção aponta as vantagens da defesa de uma revisão do antidumping à luz dos conceitos antitruste. A última seção contém as considerações finais.

\section{NOVO CICLO DE ABERTURA E CHOQUE DE COMPETITIVIDADE}

O Brasil atravessou, durante o período 1986 a 1994, um ciclo de abertura comercial caracterizado pela unilateralidade. O país atualmente tem dian- te de si um novo ciclo de abertura comercial. Em contraste com o anterior, o atual constitui uma abertura negociada em acordos bilaterais, blocos comerciais e no âmbito multilateral na OMC.

Para conseguir extrair eficientemente os ganhos de acesso a novos mercados que ocorrerão nesse novo ciclo, é necessário um choque de competitividade na economia brasileira. Isso requer a recuperação da taxa de investimento, em que o marco regulatório desempenha papel crucial, estabelecendo a importância entre regulação e investimento.

A decisão pelo investimento por parte das empresas depende da comparação entre o valor presente da lucratividade esperada do empreendimento $(\pi)$ e o custo inicial de investir (C), ocorrendo o investimento apenas quando $\pi>C$. Também é possível separar os efeitos da regulação em $\pi \mathrm{e}$ em C, tornando mais clara a interação entre regulação e investimento.

Em primeiro lugar, a regulação excessiva eleva o fator $C$ em países em desenvolvimento. De acordo com o relatório do Banco Mundial publicado em 2001, o custo médio de abertura de uma firma no último quartil dos países mais pobres do mundo ultrapassa o PNB per capita. Nos países ricos, o custo médio não atinge o nível de $10 \%$ do PNB per capita. Apesar de ser um país de renda média, o Brasil encontra-se na $71^{a}$ posição, em um ranking de 88 países, em relação à facilidade de abertura de uma nova empresa.
Além dos custos de entrada elevarem $C$ no Brasil e em outros países em desenvolvimento, a burocracia excessiva aumenta os custos de saída, por causa de ineficientes leis de falência. Segundo o trabalho de Claessens e Klapper, de 2002, Bankruptcy around the world: explanations of its relative use, o processo falimentar no Brasil dura em média 10 anos, contra três anos nos Estados Unidos e seis meses no Japão.

Cumpre agora discutir que fatores afetam $\pi$ negativamente nos países em desenvolvimento. Alguns fatores apontados na literatura são: i) falta de acesso aos mercados desenvolvidos, que restringe os ganhos de escala; ii) fragilidade de regras e instituições, que sobretaxa o empreendedor e induz gastos improdutivos; iii) instabilidade de regras do ambiente econômico.

As considerações feitas até esse ponto sugerem duas conclusões. Primeiro, uma menor regulação pode diminuir $\mathrm{C}$, o que mostra a necessidade de resgatar iniciativas de desburocratização que foram iniciadas nos anos 1980 e 1990. Em segundo lugar, uma maior regulação, pautada pela estabilidade de regras e transparência institucional, pode aumentar $\pi$.

De acordo com a literatura, há uma forte correlação entre as políticas públicas - na medida em que privilegiam o investimento produtivo em detrimento do gasto ineficiente - e o aumento da taxa de investimento, formação de capital humano e elevação da produtividade total dos fatores. Adicio- 
nalmente, verificou-se que, para uma amostra de países da OCDE, o excesso de regulação deprime o investimento, mas a regulação visando a liberalização da entrada possui um forte impacto positivo sobre o investimento.

Portanto, é preciso mais e menos regulação para elevar o investimento. Menos regulação é necessário, pois as barreiras regulatórias à entrada devem ser eliminadas para diminuir o custo do investimento (C). Por outro lado, mais regulação pró-competitiva é essencial, especialmente nos setores de infra-estrutura, para garantir a estabilidade de regras, e imprescindível para elevar a rentabilidade esperada dos investimentos no país. Tal adequação do marco regulatório é fundamental para se conseguir um choque de competitividade na economia, possibilitando que os ganhos do novo ciclo de abertura negociada sejam devidamente aproveitados.

\section{MODELOS REGULATÓRIOS, MERCOSUL E ALCA}

Nesta seção será discutida a relação das diferentes modalidades de interação entre regulação e defesa da concorrência e seus impactos no incentivo ao comércio e na formação de blocos comerciais. De fato, verifica-se uma convergência crescente entre as áreas de defesa da concorrência e regulação, tornando mais complexa a tarefa de delimitação de fronteiras entre as duas áreas.

Preliminarmente, devem ser ressaltadas as diferenças entre regulação e antitruste. A evolução histórica dessas duas políticas, a partir do século XIX, sugere uma delimitação de suas fronteiras, que, à primeira vista, pareceria óbvia. A defesa da concorrência visaria assegurar o funcionamento dos mecanismos de mercado. Em contraste, a regulação tradicional objetivaria substituir estes últimos, diante das falhas do mercado consideradas insuperáveis.

A defesa da concorrência tem caráter mais geral do que a regulação. Em princípio, esta última deveria existir quando houvesse uma falha de mercado cujo custo fosse superior ao da intervenção governamental. Assim, a atividade regulatória pressupõe uma determinada estrutura de mercado. Em contraste, a defesa da concorrência atua inclusive sobre a estrutura de mercado e pode, em determinadas circunstâncias, prevenir configurações anticoncorrenciais, tornando prescindível a própria regulação.

O foco da agência de defesa de concorrência está nos mercados não competitivos, nos quais há maior probabilidade de ocorrência de ilícito em função da existência de poder de mercado. Porém, uma parcela razoável dos problemas está associada a falhas de regulação. Assim, o estabelecimento de regras pró-concorrenciais pode eliminar, ou pelo menos atenuar, as falhas de mercado. Por exemplo, uma regulamentação adequada de empresas de telefonia celular ou de planos de saúde poderia diminuir o número de problemas nessa área. Portanto, a autoridade de defesa da concorrência não prescinde da autoridade regulatória nos mercados menos competitivos.

O foco da agência regulatória setorial reside nos monopólios naturais temporários. As condições de produção nestes últimos fazem com que uma única empresa tenha custos marginais sempre decrescentes à medida que aumenta sua atividade, fazendo com que a maneira mais eficiente (isto é, de menor custo médio) seja a produção por uma única firma. Daí a necessidade de o regulador estabelecer regras setoriais específicas que impeçam o monopolista natural de abusar de sua posição.

Tal atividade guarda estreita relação com a atividade da autoridade de defesa da concorrência. Isso porque a boa regulação é aquela que mimetiza da melhor maneira possível o mercado competitivo, fazendo convergir o objeto de análise dos dois tipos de autoridade. Na prática, um segmento regulado abrange vários subsegmentos que não são necessariamente monopólios naturais e que, portanto, prescindiriam de regulação específica.

Nota-se o caráter dinâmico da delimitação entre monopólios naturais e mercados competitivos: como as condições de custo, tecnologia e demanda variam significativamente no tempo, os monopólios naturais são temporários; portanto, aquilo que deveria ser regido por uma agência regulatória pode passar a requerer apenas a regra de mercado. Assim, qualquer que seja a configuração institucional escolhida, para um país ou para um setor, o dinamismo dos mercados e o elevado ritmo de inovação tecnológica recomendam um arranjo suficientemente flexível para que a inércia burocrática não represente entrave ao desenvolvimento.

A tendência moderna é a da convergência entre a defesa da concorrência e da regulação. De fato, esta última tende a definir uma função objetiva com número menor de argumentos, prioriza mecanismos que mimetizam o mercado e que, portanto, prescindem de monitoramento contínuo e/ou de uma abordagem exclusivamente setorial.

As legislações modernas procuram respeitar o devido processo legal, assegurando no plano administrativo as salvaguardas de ampla defesa, contradição e transparência. Conseqüentemente, o conhecimento jurídico será cada vez mais necessário e indispensável. Tais cuidados, aliados a uma perspectiva mais geral e não setorial, diminuem a probabilidade de captura dos regulados pelos reguladores.

Na mesma direção, a disseminação 
de legislações de defesa da concorrência em países em desenvolvimento realçou novas dimensões dessa área de política pública. O forte legado intervencionista dessas regiões deixou clara a necessidade de se promover um ambiente concorrencial em segmentos historicamente submetidos a forte regulação. Assim, em contraste com as jurisdições maduras, os late comers em defesa da concorrência acentuaram a convergência do ambiente antitruste com o de regulação.

Naturalmente, a transposição de tais tendências que se verificam no plano conceitual para o plano institucional constitui tarefa extremamente difícil, especialmente em jurisdições mais maduras, em que o espaço tradicional de cada tipo de agência já está bem delimitado e seu redesenho enfrenta notável resistência burocrática.

As considerações anteriores tiveram a intenção de explicar a diversidade de configurações institucionais no tempo e no espaço. De fato, verifica-se uma multiplicidade de arranjos institucionais em relação aos vários países e em relação a um mesmo país, de acordo com os diferentes segmentos e fases de desenvolvimento.

Tal diversidade institucional não reflete apenas as diferentes opções de política por parte do legislador, mas corresponde a um estágio específico de desenvolvimento, sobretudo em sua dimensão tecnológica. Com isso, vale discutir quais as alternativas de divisão eficiente de trabalho entre os dois tipos de agência nas áreas crescentes de intersecção entre regulação e defesa da concorrência.

É possível imaginar quatro opções para a relação entre a defesa da concorrência e da regulação. Para o entendimento da divisão estabelecida, é útil distinguir três funções: i) regulação técnica (RT), que estabelece normas, padrões e metas a serem adotados pelos agentes privados de um setor regulado; ii) regulação econômica (RE), que estabelece condições de preços, tarifas e quantidades a serem observadas pelos agentes privados no fornecimento de bens e/ou serviços regulados; e iii) lei de concorrência (LC), a principal peça legal do ordenamento jurídico do país que disciplina a livre concorrência.

As quatro alternativas ilustradas a seguir correspondem às diferentes distribuições das três funções descritas acima:

a) isenção antitruste: agências regulatórias (AR) aplicam legislação de defesa da concorrência, prevalecendo sempre a legislação específica sobre eventual comando geral da lei antitruste. Nesse caso, a agência regulatória realiza as três tarefas assinaladas acima, recaindo a ênfase sobre aspectos regulatórios, sem deixar espaço para a atuação da autoridade de defesa da concorrência (AC). Podem-se até mesmo conceber situações em que a lei de concorrência não se aplica;

b) competências concorrentes: tanto as autoridades de defesa da concorrência quanto as regulatórias têm competência para aplicar sanções antitrustes, bem como para estabelecer normas de regulação econômica;

c) competências complementares: as atribuições entre as duas autoridades não se sobrepõem. Há nítida divisão de trabalho segundo a qual a agência regulatória cuida exclusivamente das tarefas de regulação técnica e econômica, enquanto a autoridade de defesa da concorrência aplica a lei antitruste; $e$

d) regulação antitruste: a autoridade de defesa da concorrência aplica tanto a lei antitruste quanto as regulações técnicas e econômicas. Trata-se de caso simétrico ao descrito em a), em que a ênfase maior recairia sobre a legislação antitruste, restringindo-se a regulação ao mínimo necessário.
A diversidade de uma economia moderna faz com que as quatro situações anteriores, bem como algumas de suas variantes, possam ser identificadas simultaneamente em um mesmo país, de acordo com a história institucional e as especificidades de cada setor.

Alguns exemplos parecem representativos de cada uma das configurações acima. O setor agrícola dos Estados Unidos constitui notória ilustração de isenção antitruste (M1). Naquele país, a competência concorrente entre duas ou mais agências ocorre em mais de um setor, como o bancário (M2). No segmento de telecomunicações no Brasil, o sistema adotado se aproxima do sistema de competências complementares (M3). $\mathrm{Na}$ Austrália, a autoridade antitruste encampou as tarefas de regulação (M4).

Essas possibilidades descritas parecem compatíveis com o elenco de alternativas de configuração institucional sugerido em um relatório do Banco Mundial de 1998. Nesse estudo se destaca a alternativa de a autoridade de defesa da concorrência se tornar uma corte administrativa para recursos de decisões de agências regulatórias. Isso seria compatível com uma ou mais variantes das configurações discutidas. Pode-se imaginar, por exemplo, na hipótese do sistema de competências complementares, que, tão-somente nos casos que envolvessem matéria antitruste, as agências regulatórias seriam transformadas em órgãos de instrução que emitiriam decisões a serem recorridas de ofícios a tribunais da concorrência de caráter administrativo.

A escolha de uma configuração institucional ótima não é um processo simples, nem seria razoável afirmar que existe um único modelo a ser adotado. As diferentes configurações apresentam vantagens e desvantagens, dependendo de conjunturas e situações 
específicas. A escolha deve levar em conta pelo menos cinco fatores:

1) Flexibilidade institucional: o elevado ritmo da mudança tecnológica pode transformar um antigo monopólio natural em mercado concorrencial, exigindo uma mudança regulatória. Na mesma direção, novos processos produtivos e o surgimento de novos produtos podem alterar o grau de substitutibilidade na demanda e/ou na oferta. Assim, seria desejável que os órgãos regulatórios fossem suficientemente flexíveis para lidar com tais mudanças estruturais.

2) Eficiência e capacidade de decisão em tempo econômico: o ritmo da atividade econômica requer decisão rápida e segura. Processos burocráticos morosos aumentam a incerteza, diminuindo a rentabilidade esperada do investimento.

3) Custo burocrático de transação: analogamente à noção de custos de transação da teoria da firma, é útil definir o custo burocrático de transação como aquele associado à elaboração de acordos e rotinas operacionais interinstitucionais.

4) Minimização do risco de conflito de competências: quando mais de uma instituição tem atribuição em certa matéria ou quando duas ou mais instituições têm competências próximas, surge o risco de um conflito de competência que pode acarretar demora, incerteza e, conseqüentemente, insegurança jurídica.

5) Minimização do risco de captura: as experiências regulatórias anteriores de alguns países revelam uma elevada probabilidade de "captura" das agências regulatórias pelos segmentos que deveriam ser regulados. Independentemente de problemas éticos, verificou-se elevada propensão de os "regulados capturarem os reguladores" em virtude da assimetria de informação em desfavor do setor público e da natural identidade profissional entre os especialistas com função judicante temporária e os segmentos sujeitos a uma determinada jurisdição administrativa. $\mathrm{O}$ grau em que o recrutamento e o futuro profissional das autoridades regulatórias se restringe ao setor regulado constitui variável relevante para a propensão à captura.

O Modelo $1\left(M_{1}\right)$ - de isenção antitruste - não apresenta a flexibilidade desejada, pois não há incentivos para a autoridade regulatória eliminar os controles sobre o mercado na hipótese de mudanças estruturais. Em compensação, dada a concentração de atividades em uma instituição, é possível supor que haja economias de escala. Por outro lado, o risco de captura é elevado, pois tipicamente esse desenho privilegia órgãos setoriais especializados com forte identidade com os segmentos que deveriam, em princípio, monitorar e fiscalizar. Destaque-se, por fim, a vantagem de não haver risco de conflito jurisdicional.

O Modelo $2\left(\mathrm{M}_{2}\right)$ - de competências concorrentes - acusa maior flexibilidade institucional na medida em que incorpora uma autoridade que, em princípio, estaria propensa a promover a concorrência e não teria resistência burocrática à eliminação da regulação setorial. Perdem-se, contudo, eventuais economias de escala, uma vez que se introduz nova estrutura burocrática. A sobreposição de funções tende a eliminar, igualmente, economias de escopo. Em compensação, diminui o risco de captura ao introduzir uma outra agência que, em princípio, zelaria pela ótica mais geral da defesa da concorrência.

O Modelo $3\left(\mathrm{M}_{3}\right)$ - de competências complementares - é similar ao de competências concorrentes, exceto pela especialização das autoridades regulatórias em regulação técnica e econômica, e das de defesa da concorrência na aplicação da legislação antitruste. Tal como no Modelo 2, isso eliminaria eventuais ganhos em economias de escopo. Além de manter os ganhos em termos de menor risco de captura, esse modelo tem a vantagem de apresentar menor potencial de conflito entre jurisdições, uma vez que os papéis de cada órgão não se sobrepõem.

O Modelo $4\left(\mathrm{M}_{4}\right)$ - de regulação antitruste - somaria aos ganhos do Modelo 3 eventuais economias de escopo, aliadas à redução do custo burocrático de transação pelo fato de o processo decisório envolver uma única agência. Assim como no Modelo 1, e teoricamente no Modelo 3, não há risco de conflito jurisdicional. Em se tratando de uma única agência, supõe-se que o risco de captura seja relativamente maior, ainda que atenuado pelo fato de se tratar de órgão geral e não meramente setorial.

Dois critérios podem ser úteis na escolha de uma configuração ótima. O primeiro é a existência ou não de economias de escopo e escala nas atividades regulatórias setoriais, e entre defesa da concorrência e regulação; o segundo são os custos burocráticos de transação entre unidades relativamente autônomas.

O Quadro 1 contém as possibilidades a serem consideradas. Ao se verificar que os custos de transação e as economias de escala e escopo assumem uma grande importância relativa, os Modelos 1 e 4 teriam preferência. Por outro lado, ao se entender que os custos de transação e as economias de escala e escopo não têm grande importância, os Modelos 2 e 3 pareceriam vantajosos.

Porém, a construção institucional não ocorre no vazio. É importante o ponto de partida em termos de recursos materiais e humanos. Por exemplo, se o setor bancário tem sido tradicionalmente regulado por um ban- 
co central bastante ativo na área regulatória, haverá provavelmente uma tendência a estender sua atuação à área de defesa da concorrência, tornando mais difícil um sistema de competências complementares ou mesmo concorrentes. Em tais situações, o custo de transição pode ser elevado ao suscitar eventuais conflitos de jurisdição e/ou requerer o desenvolvimento de expertise setorial em um espaço de tempo relativamente curto. Isso justificaria uma estratégia especial, inclusive, por exemplo, um cronograma mais dilatado de mudança institucional.

Assim, nota-se que a decisão a respeito do modelo institucional a ser adotado em cada país e em cada setor econômico envolve diversas variáveis, devendo sempre levar em consideração a experiência em sua dimensão histórica.

Cumpre agora discutir a relação entre a escolha de modelos institucionais e a formação de blocos econômicos. Para isso, é útil distinguir entre as óticas regulatória e concorrencial. A ótica concorrencial se diferencia ao tentar evitar o exercício de poder de mercado e dar maior ênfase à diminuição das barreiras à entrada. Dentre as barreiras à entrada que a regulação concorrencial visa diminuir, inserem-se aquelas que afetam a mobilidade de bens e serviços e de fatores. Portanto, é possível associar arranjos regulatórios dotados de ótica concorrencial aos modelos M3 e M4, com diminuição das barreiras regulatórias, inclusive as que afetam o comércio. Assim, é possível afirmar que a regulação concorrencial tende a fortalecer a formação de blocos comerciais de natureza aberta nos quais a criação de comércio domine o desvio de comércio.

\section{OS ANTEPROJETOS SOBRE AS AGÊNCIAS REGULADORAS}

Cabe fazer algumas considerações sobre os anteprojetos recentemente apresentados pelo Poder Executivo que visam reformar as agências reguladoras federais. Interessa saber se os anteprojetos recentes ajudam a gerar a regulação pró-investimento e prócomércio.

Apesar de apresentar avanços importantes, principalmente por dar maior transparência ao aparato regulatório, os anteprojetos diminuem a independência das agências e não definem a interação entre elas e a defesa da concorrência.

A proposta governamental compromete a independência das agências reguladoras em três pontos principais: i) os contratos de gestão propostos objetivam compatibilizar as atividades regulatórias aos programas governamentais, confundindo a atuação técnica dos reguladores com a plataforma política do governo; ii) cria-se uma comissão de acompanhamento e avaliação diretamente subordinada à administração direta com poderes que, na prática, deverão interferir nas decisões das agências reguladoras. Dessa forma, concentra-se no Executivo uma função supervisora que seria típica de comissões especializadas do Congresso. No Brasil, tal função poderia ser executada pela Comissão de Infra-Estrutura do Senado; iii) criase a figura do ouvidor sem conferirlhe a necessária isenção e independência. Na forma proposta pelo anteprojeto, o ouvidor é um funcionário nomeado pelo presidente da República com funções que se confundem com as atribuições dos próprios integrantes das agências.

Além disso, a proposta do governo deseja promover a transferência do poder concedente para os ministérios setoriais, gerando conflito de interesse no caso de Minas e Energia, que possui assento na administração da Eletrobrás e da Petrobrás. Embora a experiência internacional seja diversificada, o problema reputacional e maior risco regulatório no caso brasileiro recomendaria deixar o poder concedente em órgãos de Estado, como as agências, e não de governo, como os ministérios.

Em segundo lugar, o projeto aborda corretamente o problema da coordenação entre os diferentes tipos de reguladores e a administração direta. Da mesma forma, contempla a articulação entre as agências federais e as estaduais, bem como a interação entre os reguladores setoriais e os órgãos de defesa da concorrência. No entanto, não se define o principal, ou seja, quem

Quadro 1 - Possibilidades de escolha, economias de escopo e custos burocráticos de transação.

\begin{tabular}{|c|c|c|}
\hline $\begin{array}{lr} & \text { CUSTOS BUROCRÁTICOS DE } \\
\text { ECONOMIAS DE ESCOPO } & \text { TRANSAÇÃO }\end{array}$ & ALTO & BAIXO \\
\hline ALTO & $\begin{array}{l}\mathbf{M}_{\mathbf{1}} \text { - Isenção antitruste } \\
\mathbf{M}_{4}-\text { Regulação antitruste }\end{array}$ & \\
\hline BAIXO & & $\begin{array}{l}\mathbf{M}_{2}-\text { Competências concorrentes } \\
\mathbf{M}_{3} \text { - Competências complementares }\end{array}$ \\
\hline
\end{tabular}


tem competência para decidir sobre abusos do poder econômico e quem tem a palavra final sobre a aprovação de fusões e aquisições. Sem tal definição, persistirão áreas cinzentas que elevam o risco regulatório.

\section{ANTIDUMPING, CONCORRÊNCIA E ALCA}

Há uma questão importante e pouco explorada pela academia e diplomacia dos países em desenvolvimento: a revisão das políticas antidumping. É sabido que uma revisão das medidas antidumping à luz dos conceitos de defesa da concorrência é essencial no combate ao protecionismo. A defesa dessa revisão estaria inserida na discussão multilateral sobre comércio e defesa da concorrência, um dos "temas de Cingapura", reforçando assim a necessidade de distinguir e dar tratamento diferenciado aos diferentes temas que formam esse grupo.

O foco da política antidumping é a defesa da indústria nacional, e não os consumidores ou a eficiência econômica, como ocorre na defesa da concorrência. O padrão de prova para condenação em antidumping consiste na comprovação de venda abaixo do valor normal e no nexo causal entre importações e danos à indústria nacional. Esse padrão não é suficientemente rigoroso, dando margem à sua utilização meramente para fins protecionistas.

Uma revisão da política antidumping à luz dos conceitos de defesa da concorrência ajudaria a impe- dir o uso protecionista da defesa comercial. No antitruste, uma prática de preços é considerada predatória apenas quando é observada s seguinte série de condições: existência de mercado relevante concentrado; posição dominante do predador; elevado nível de barreiras à entrada; excesso de capacidade instalada do predador; capacidade do predador de financiar os prejuízos iniciais da prática de preço predatório; possibilidade de expulsão dos ativos dos rivais; e prática pelo predador de preços abaixo do nível do custo variável médio.

Caso as condições não sejam observadas, não é razoável supor que a prática de preços predatórios seja passível de condenação. A última condição indica que a racionalidade dos preços do suposto predador reside na expulsão do rival, uma vez que seus lucros seriam maiores caso ele produzisse quantidade nula.

Desse modo, o padrão de prova em casos de preço predatório é mais rigoroso do que o de casos de dumping. Por sua vez, a utilização de critérios antitruste na defesa comercial diminuiria a capacidade de utilizar o antidumping para fins protecionistas. Seria ingênuo imaginar que uma mudança radical nos padrões da defesa comercial seja possível a curto e médio prazos. Entretanto, seria útil incorporar na plataforma dos países em desenvolvimento uma gradual transformação dos critérios de antidumping em direção ao antitruste. Entre outras coisas, implicaria privilegiar a defesa da concorrência entre os temas de Cingapura como uma questão alinhada com os interesses do Grupo dos 20.

\section{CONCLUSÕES}

Este ensaio procurou mostrar que o aparato regulatório tem sido um obstáculo ao comércio e ao investimento. A discussão sugere três direções para a política pública.

A primeira é a necessidade de eliminar o excesso de regulação e barreiras à entrada. Ao mesmo tempo, é preciso conferir um caráter pró-concorrencial à regulação nos segmentos de infra-estrutura. Os anteprojetos recentes do Executivo brasileiro não ajudam a incentivar o comércio e o investimento, pois diminuem a independência das agências e não definem a divisão de tarefas entre o aparato antitruste e o regulatório.

A segunda é uma divisão adequada entre reguladores setoriais e autoridades antitruste no plano nacional, que pode fortalecer blocos comerciais de natureza aberta nos quais a criação de comércio domine o desvio de comércio.

Por fim, a terceira é do interesse dos blocos comerciais e dos países em desenvolvimento em particular, ao propor a transformação gradual dos critérios antidumping em critérios de defesa da concorrência, permitindo a expansão do comércio e maior acesso aos mercados.

Um esforço sistemático nessas direções poderia dar sustentação a um choque de competitividade capaz de preparar o país para um ciclo de abertura negociada.

Pensata recebida em 12.02.2004. Aprovada em 19.05.2004.

\section{Gesner Oliveira}

Professor do Departamento de Planejamento e Análise Econômica Aplicados à Administração da

FGV-EAESP. Doutor em Economia pela University of California.

E-mail: gesner@fgvsp.br 